\title{
The ELENA Programme in the Province of Chieti - A Public Private Partnership Best Practice Improving Energy Efficiency of Buildings and Public Lighting Systems
}

\author{
Pierluigi Fecondo ${ }^{* 1}$, Giancarlo Moca $^{2}$ \\ ${ }^{1}$ Department for Energy and Sustainable Development, Province of Chieti, Chieti, Italy \\ e-mail: pfecondo.elena@provincia.chieti.it \\ ${ }^{2}$ Department for Energy and Sustainable Development, Province of Chieti, Chieti, Italy \\ e-mail: g.moca@provincia.chieti.it
}

\begin{abstract}
Cite as: Fecondo, P., Moca, G., The ELENA Programme in the Province of Chieti - A Public Private Partnership Best Practice Improving Energy Efficiency of Buildings and Public Lighting Systems, J. sustain. dev. energy water environ. syst., 3(3), pp 230-244, 2015, DOI: http://dx.doi.org/10.13044/j.sdewes.2015.03.0018
\end{abstract}

\begin{abstract}
Public Private Partnership initiatives and models are proven, scalable and internationally-recognized procurement methods for reducing the operating costs and improve environmental quality of public bodies. However, there are still barriers to overcome. Local communities' engagement, lack of technical knowledge and financing constraints are just some topics that still need reliable solutions. The governance model that is adopted for the "Chieti Towards 2020" Project, which was funded under the European Local Energy Assistance in the 2012-2014 period, try to operate a "glocal" synthesis between local instances and global issues. A mixed bottom-to-top and top-to-bottom approach involves local communities' trying to address requirements through centralized, high-level management and coordination activities. To date, the most relevant Project outcomes consist of 87 municipalities involved, a structured database of energy audit and data about 144 buildings and about 46,000 public light points. Moreover, an effective engagement of public and private stakeholders lays the foundation for a strong Energy Performance Contract framework able to leverage financing based on minimum guaranteed energy savings of $20 \%$ in respect to baseline values.
\end{abstract}

\section{KEYWORDS}

ELENA, Public Private Partnership, Energy efficiency support schemes, Renewable energy, Third party financial mechanisms, ESCOs, Energy Performance Contract.

\section{INTRODUCTION}

The IEA report on Energy Efficiency Governance [1] pointed out the importance of engaging the private sector in implementing Energy Efficiency (EE) policies and programmes. That study defined the concept of Public-Private Partnership (PPP) as "voluntary efforts in which government and the private sector collaborate to analyse public policy problems and jointly implement solutions. PPPs work most effectively when they focus on a specific issue or problem (i.e. are programmatic), involve broad engagement with private-sector entities, and include some form of co-financing on technology or concept development or demonstration".

The concept of PPP has been popular since the early 1990s, and many different models exist $[2,3]$. PPP generally involve a contract between a public agency and a private party, in which the private party provides a public service or project and assumes

* Corresponding author 
substantial financial, technical and operational risk in the project. The structure has the advantage of promoting rapid implementation of projects without burdening public finances and can provide better value for money for the public sector.

It allows the State or local authorities to involve a private enterprise in both the financing and management of a public service. Generally, the public sector is responsible for monitoring and evaluating the quality of interventions, while the private sector is responsible for project implementation and service delivery. Several countries in the European Union (EU) have established the legal framework for the implementation of a PPP, both nationally and in the context of cross-border projects [4].

In recent years, PPP structures have been widely used in EE implementation and finance, as it has become a priority for the public sector. The PPP provides an effective framework, since government and/or local authorities do not have the technical and, mostly, financial ability to invest large amounts of public funding as subsidy in this sector. It also allows governments to achieve their EE targets with only a fraction of the public funding that would otherwise be required, with the private sector taking on both the financial and performance risks. The main procurement method to put in action a PPP in EE projects is the Energy Performance Contract (EPC).

Under an EPC, an Energy Services Company (ESCO) with strong technical know-how and capabilities provides a comprehensive building retrofit, which can include the replacement of boilers, insulation, cooling systems, and lighting and temperature automation controls, as well as the integration of energy data management software and on-site renewable energy systems. The ESCO assumes complete "turn-key" responsibility for the project. This means that it covers all aspects of the project from the planning and project phases to the end of contract, such as preliminary and detailed energy audits, engineering studies, business case analysis, installation, commissioning and performance measurements. Importantly, the ESCO assumes performance risk for the project in the form of a long-term financial guarantee to ensure that the projected energy, water and operational cost savings materialize and are preserved over time.

However, there are several key barriers that must be addressed before the market for performance contracting under PPP framework will be widely and effectively used in Europe. A number of studies and researches have been carried out on this topic $[5,6]$, mainly based upon case studies analysis and multi-annual follow up results. Most of the available literature observes significant barriers especially from the public sector's point of view, focusing on some key topics as follows:

- Lack of awareness about EPC among public decision-makers and civil servants;

- Lack of policies and support mechanisms in order to use common and harmonized laws and processes;

- Constraints in public bodies' technical capacities to make energy audits and inventory of public buildings;

- Inflexible budget rules and financing constraints that undermine the incentive to save energy and reduce expenditure through performance contracts or other means.

More recently, The European Investment Bank (EIB) [7], pointed out also to projects' profitability compared to their size and energy consumption. For example in small projects, the transaction costs that are involved may be substantial and affect their profitability adversely, so is not easy to leverage financing based on future guaranteed energy savings.

In order to overcome the above mentioned barriers and to help local authorities to mobilize private investment in the public sector, the EU and EIB have launched the European Local Energy Assistance (ELENA) facility. 
The ELENA Programme is essentially focused on PPP mechanism, implementing Third Party Financing (TPF) and Saving Shared Contract model. Energy efficiency measures and interventions will be charged on ESCOs at no cost to the public administration. Investments are rewarded through savings achieved by improved energy performance of a building or a facility in the case of EE or through "feed-in tariff" in the case of energy conversion from renewable sources. Any performed intervention foresees the assignment of the facility or building management for the benefit of the private company that carried it out, for a given number of years, after which administrations will hold their own property and the implemented improvements, fully enjoying all the benefits in energetic and economical terms. ELENA is basically a project development assistance facility. The ratio of funding is to provide grants to cities, provinces, regions and entities acting on their behalf, of up-to $90 \%$ of eligible costs.

Within the ELENA framework, "Chieti Towards 2020" is the project carried out by the Province of Chieti, for the implementation on the territory, of bankable and sustainable investment projects in the fields of EE and RES in the 2012-2014 period.

The project includes measures of energy efficiency on buildings of the Province of Chieti and of the Municipalities within the provincial territory as well as implementation of RES and optimisation of public lighting systems. The ELENA Contract between the European Investment Bank and the Province of Chieti was signed on November $3^{\text {rd }}, 2011$ and January $1^{\text {st }}, 2012$ marked the beginning of project activities.

The role played by the Province of Chieti concerns the coordination and supervision of technical and legal activities, from preliminary and early project stages to call for tenders and subsequent contract arrangements for interventions included in the Project.

The next section shows methodology and results obtained through the analysis of the implementation "Chieti Towards 2020 Project" with the purpose of identifying an effective PPP and governance model in improving the quality of energy and environment in the public sector. The paper will also highlight the key factors for success and analyse those critical to outline, more generally, the salient features of a good practice that aims to overcome some typical barriers of PPP in EE projects development, with high reproducibility and adaptability features.

\section{LOCAL ENERGY EFFICIENCY DEMANDS AND PUBLIC PRIVATE PARTNERSHIP FRAMEWORK}

The Province of Chieti has a territorial area of about $2,588 \mathrm{~km}^{2}$, with 104 Municipalities and a variety of urban settlements, nature environments and climate conditions (Figure 1).

Local targets for EE, RES and $\mathrm{CO}_{2}$ reduction are stated in the Sustainable Energy Action Plans (SEAPs) that each of 104 Municipalities of the Province of Chieti has drafted within the Covenant of Mayors agreements. All SEAPs to date have been approved by the EU Commission.

Most common actions proposed into SEAPs include building refurbishment for energy EE, that have initially been taken into account for SEAPs actions, to date are not included into ELENA due to changes in Italian incentive framework. Indeed, the current photovoltaic developing strategy at national level doesn't include significant incentives as it was in the recent past. Thus the private market doesn't consider so attractive investments in photovoltaic systems, in respect to other typologies of RES. However, due to lack in EPC awareness, technical capabilities or funding availability for public bodies, many of these proposals could be not put into action without an external aid. Furthermore, dealing with municipalities, the development of the EE potential often implies to consider a large number of small investments. Depending on the way these 
projects are implemented, the transaction costs involved may be substantial and affect their profitability. In fact the EPC model is suitable for some energy services in some circumstances and not for others. Several researches and applications upon energy service contracting have been carried out and successfully tested in numerous applications drawing ideas from Transaction Cost Economics theories [8, 9].

High transaction costs, considered as a relevant part within the overall production costs supported by an ESCO [10], are often significantly related to information and procurement costs and this makes for unfavourable PPP frameworks.

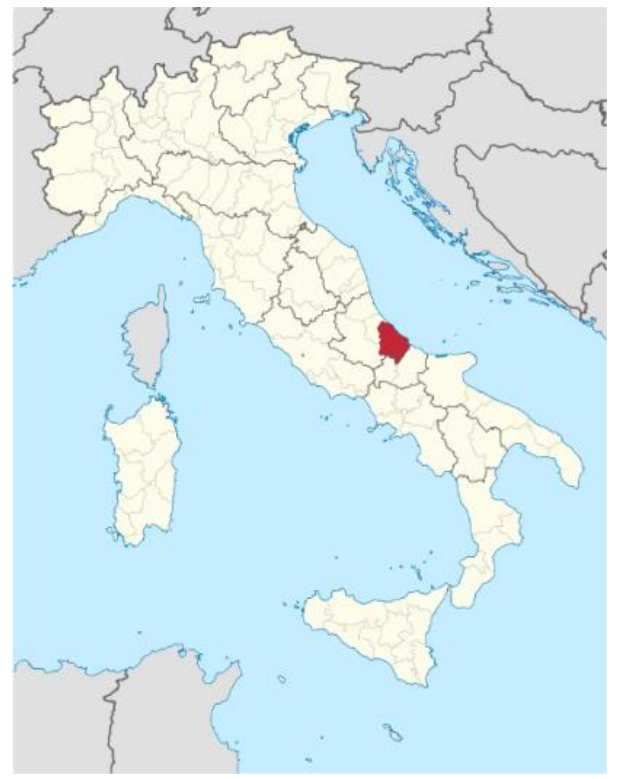

(a)

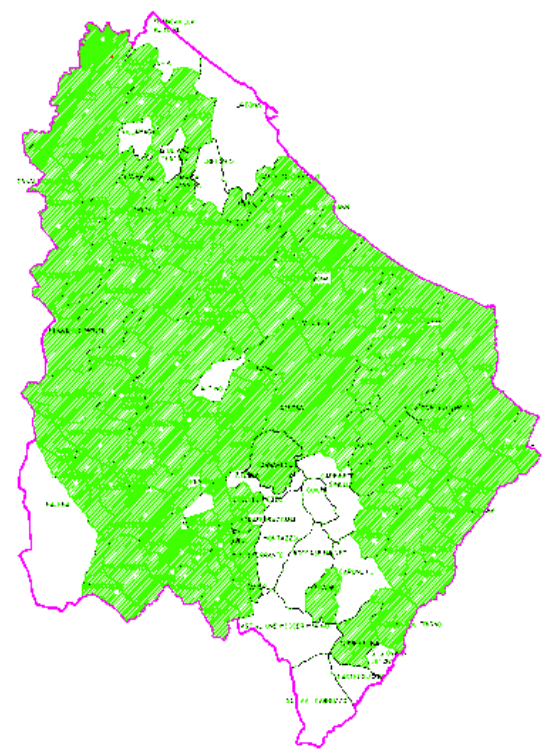

(b)

Figure 1. Location of Province of Chieti (a); Geographical distribution of Municipalities involved in the "Chieti Towards 2020" Project (b)

Developing approaches that reduce these transaction costs is therefore necessary and two main options can be considered [11].

The first option considers standardization and scalability of technical procedures and projects a key factor in order to reduce the costs for access to information at the planning and implementation levels.

The second option is based upon the tendency by ESCOs to do one large deal rather than lots of small deals. The aggregation of small and scattered projects over the territory into an unique and bigger lot with replicable and scalable interventions, make energy investments more attractive.

Thus, a first step to reduce implementation costs and make investments more attractive to the ESCOs' market, was to demand technical activities from municipalities to the Province of Chieti. Following first a bottom-to-top approach, Municipalities have formally applied and accepted Programme conditions and have signed the specific agreement pursuant to Italian laws. To date, formal agreements have been signed by 87 Municipalities, 21 of which are above 4,000 residents. The agreement contains annexes with list of buildings or intervention to be made within the PPP framework. The role played by the Province of Chieti concerns the coordination and supervision of technical and legal activities, from preliminary and early project stages to call for tenders and subsequent contract arrangements for interventions included in the Project [12]. Figure 2 shows the geographical distribution of Municipalities involved over the entire Provincial 
territory, meaning the vast territory involved in the Project and the diversity of its characteristics as demographic and orographic factors and local climatic features.

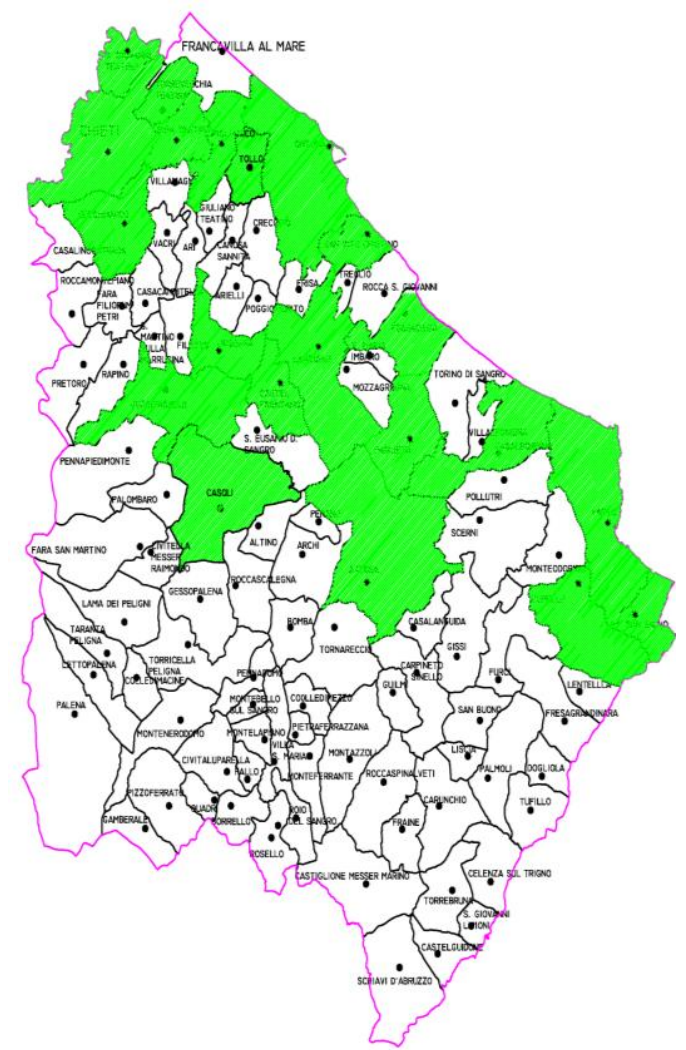

(a)

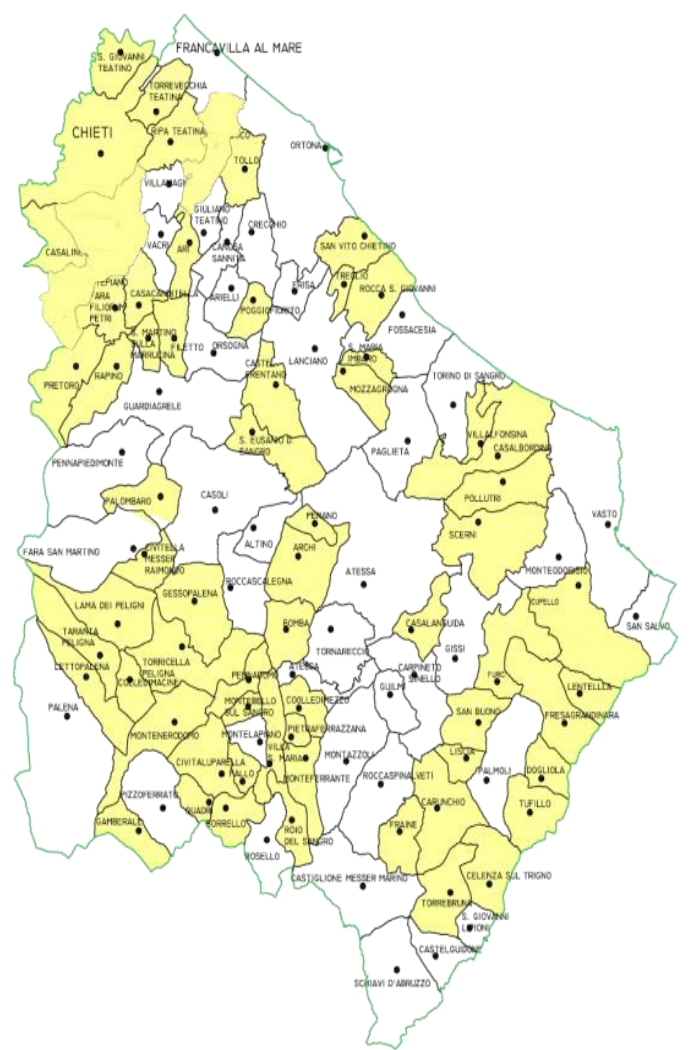

(b)

Figure 2. Municipalities above 4,000 residents (a); Municipalities with interventions on public lighting systems (b)

The Province of Chieti, as leading Public Administration promoter, may represent the geographic intermediate "glocal" level administration. Its role is to listen and synthesize the expectations and interests of local communities within the territory. The technical support provided must be able to transfer, at the local scale, the most general and global mechanisms for the development of the complex programs in the field of EE and RES.

The aim is to create a mechanism for the energy efficiency refurbishment of buildings and public lighting system, which could be an undeniable driving force for the local economy in terms of direct and induced labour, without affecting public finances. This can be achieved using the ELENA facility to create the legal technical requirements for investment through "tender" and then use the investment capacity of eligible private individuals, with the support of the EIB in terms of money loan.

As a first step to implement the investment program, the Province of Chieti has adapted its own administrative and technical structure, working through its own offices and in particular, through the environment and energy, construction, transport and general accounting departments. The facility is technically supported by the participating companies Alesa Srl and Ops Spa, as well as by the technical services of the participating municipalities. These structures are moreover supported by external experts. The scope of engaging a specific expert authority is to provide technical, legal and accounting guidance for the preparation of all the preliminary documents required by current mandatory public procurement and contract legislation. The framework of the adopted organization and support structures is shown in Figure 3. 


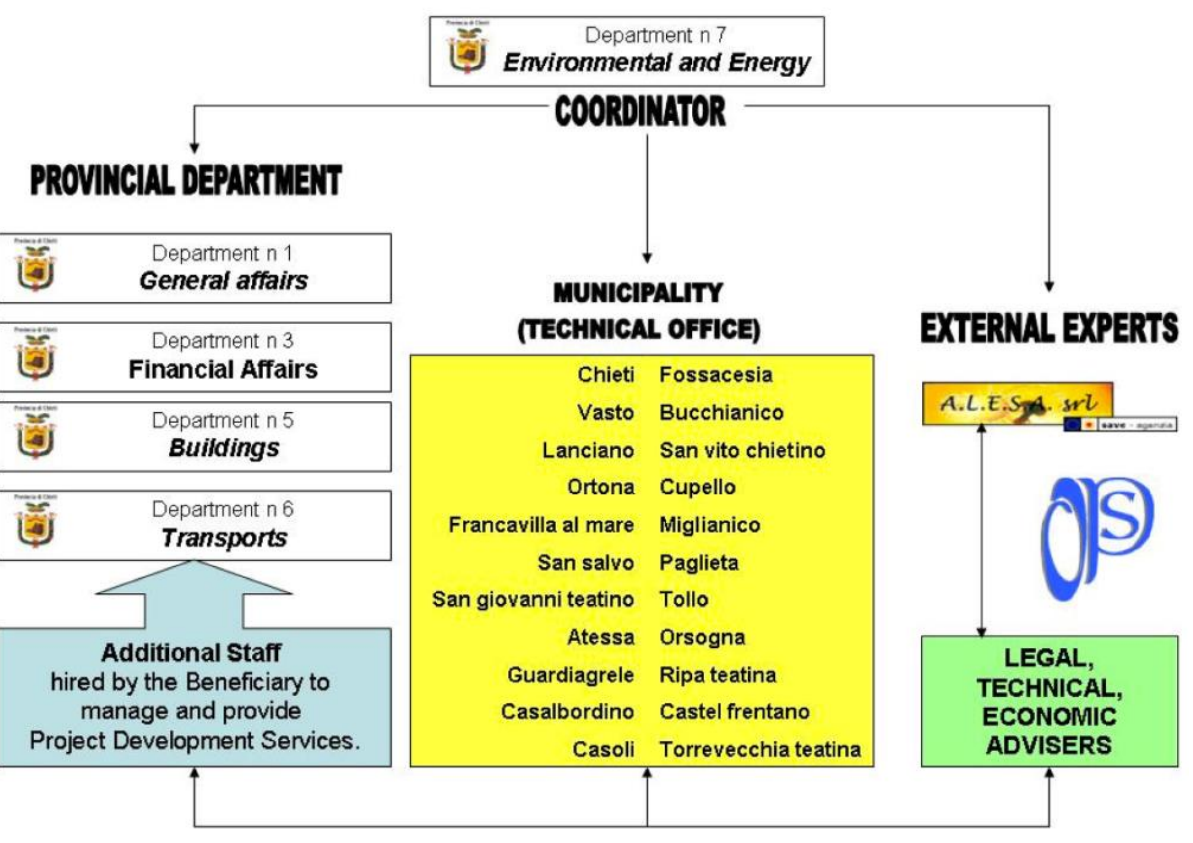

Figure 3. Framework of organization and support structures adopted for PPP mechanism

Drafting the public call for tenders for the award of EPC contracts is a fundamental stage in order to achieve the Project's objectives and to supply contract conditions that will allow the ESCOs to manage activities and, at the same time, provide protection for local administrations in their quest to achieve energy efficiency and savings targets. The overall estimated investment is EUR 80 million. The share of 60 million will be provided by loans provided by the European Investment Bank through a national financial intermediatory and the remaining 20 million, from resources provided in equity by the ESCOs. The logical flowchart of PPP scheme is shown in Figure 4.

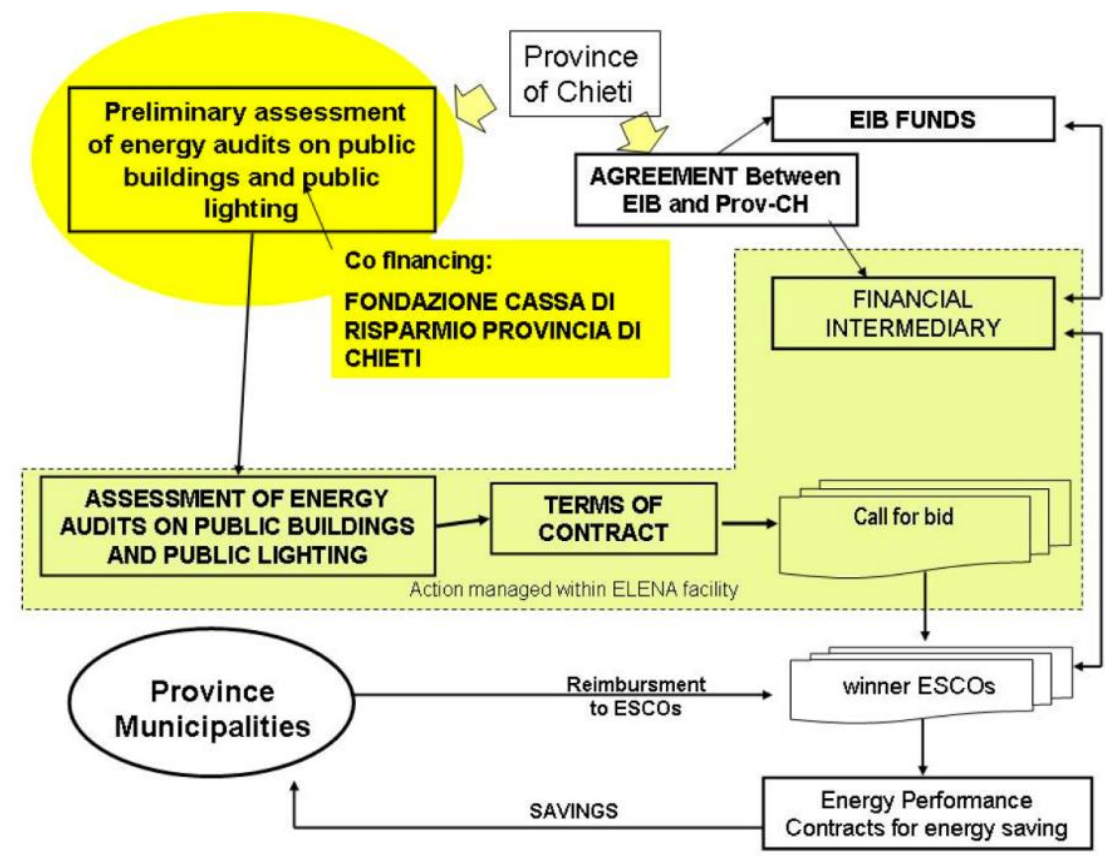

Figure 4. Flowchart of PPP funded by European Bank of Investment within the "Chieti Towards 2020" ELENA Project 
The advantages of this kind of approach are many. Small and medium municipalities lack "know how" and human resources, both technical and legal, in order to organize and manage a complex EPC framework. This means that, from early stages to energy audits, call for tenders and subsequently multiannual dealing with ESCOs, municipalities need an external qualified support. On the other side, ESCOs have enough high level technical and economical capabilities and skills to offer services that could be more favorable for them, with a high "moral hazard" potential.

In order to preserve public interest and at the same time make investments attractive for the market, a top-to-bottom approach has been implemented. The ELENA teamwork of experts allows the Province of Chieti having the appropriate advanced skills and knowhow in order to evaluate investments and interventions, prepare tenders and management contracts advantageous for the public and equitable for private companies. Morevoer, this kind of centralized approach reduces notably the costs for implementing EPC schemes.

Another advantage resulting from grouping municipalities and small projects within a larger framework, is the possibility of making profitable interventions that, taken individually, would not be there otherwise. For example it would be unattractive in terms of absolute revenue, for an ESCO, an EPC contract for municipalities with just 100 light points, while an aggregate of 10,000 represents an interesting corpus for public lighting facilities business.

\section{IMPLEMENTATION METHODOLOGY AND ACTIVITIES CARRIED OUT}

The intervention strategies and technical activities carried out concern about 200 public buildings and around 46,000 light points involved in the Project. All activities are managed by the Province of Chieti in agreement with the Municipalities and other public entities involved in the project, and must be able to transfer, at the level of local communities, technologies and practices of global significance with distinct characteristics of innovation and complexity.

This is moreover true in a territorial context where geographical distances, cultural differences even at local level and "centrifugal" peripheral boosts, represent critical factors for targets achievements. Sustainability issues often require changes at local level in order to satisfy the burden sharing strategies for global $\mathrm{CO}_{2}$ reduction.

One of the Project's main challenges is thus represented also by finding a "glocal" dimension to act within. In this scenario, it is necessary to identify and resolve differences and conflicts between extreme positions. Dealing with differences, it is possible to run up against conflicts concerning global and local level policies and strategies. Sustainability issues require a revision of models, habits, behaviours by people and governments, in order to achieve results in the medium and long term. This is neither simple, nor easy. As Latouche commented: "[...] taking into consideration great ecological balances means to put under discussion some aspects of our growth model, as well as our way of life" [13].

The introduction of new methods and technologies in the energy field makes it difficult to recognize local and global dimensions just on the basis of a spatial scale. For example, the remote control, management and optimization of public lighting systems and building HVAC efficiency, does not require the human control and presence at local level anymore nearby a building or in a town. The management of units scattered in space and at the same time unified and decentralized, features a "space without soil" $[14,15]$. Traditional policy rules and local governments are usually very resilient to this change of perspective, especially when the PPP framework is managed by another public body at an upper and central level. 
In order to overcome this barrier, it is very important to set clear rules for all activities and promote information and communication activities during all stages of Project development.

\section{Technical activities}

Technical support activities within the "Chieti Towards 2020" ELENA Project started in the month of December 2012 and were, from the earlier stages, addressed to the definition of documents regarding the energy audits and assessments of buildings and public lighting systems. The basis of this work is represented by a preliminary but detailed analysis of the achievable energy saving targets with interventions on building envelopes and heating systems. The preliminary analysis was not funded by ELENA program, since the Province of Chieti has found appropriate external resources (EUR 100,000 from the Foundation of "Cassa di Risparmio di Chieti").

During this stage, a clear and understandable technical framework has been developed and shared with municipalities and external professionals for energy audit campaign. This framework is essentially based upon two important set of activities.

The first set of activities consists in grouping criteria for energy audits by buildings consistency and municipalities spatial distribution on the provincial territory. This was necessary to make some aggregations of buildings and public lighting systems in order to assign an equal economic value of external energy audits and assessment for professional services.

The second set concerns drafting technical specifications and terms of reference for detailed energy audits professional services, in order to make auditing activities as homogeneous as possible in terms of methods and procedures for data acquisition and processing. This was necessary in order to make calculation results to be verifiable, comparable and reproducible and setting the partnership's rules between the public body and the private professionals engaged for energy audits.

The technical specifications, drawn up for both buildings and public lighting, include the requirements and minimum contents of assessments to be executed in accordance with the general scheme of the UNI CEI TR 11428 technical regulations, the papers and documents to be delivered to the Province of Chieti and the terms and forms of presentation of the energy audit report [16-18]. Technical specifications also contain references to the technical standards to be used in the calculations, energy consumption over the past 3 years (such as energy consumption, costs and use profiles, maintenance, replacements, etc.) and rules for the implementation of instrumental diagnostics on buildings (such as infrared thermography). For each examined building, a full and comprehensive energy analysis has been carried out, taking into account both qualitative and quantitative parameters. Infrared thermography used in order to identify problems in thermal insulation of building envelopes and energy modelling through suitable simulation tools, also with 3D interfaces and visualization aids, allowed understanding thermal behaviour and critical issues. Figures 5 and 6 show examples of energy diagnostics and modelling performed on all buildings involved.

Once the dataset was complete with all the information and all the details that had emerged during the auditing activities, a technical assessment was performed in order to determine the eligibility, convenience and evaluation of the energy saving and efficiency investments to be made and to be included in the public call for tenders for ESCOs. One of the main issues to consider while evaluating energy saving potential is the payback time. According to the ELENA facility rules, the duration of EPC can be at least 15 years. Thus the payback time of interventions has to be considerably below this cap. The critical factors to be considered to evaluate energy saving potential, deal with "how much" the 
buildings are used, "who" can take advantage from energy efficiency improvements and maybe most important of all, "how much" energy is used. These are crucial considerations within a PPP framework and several obstacles can be identified about buildings' eligibility.

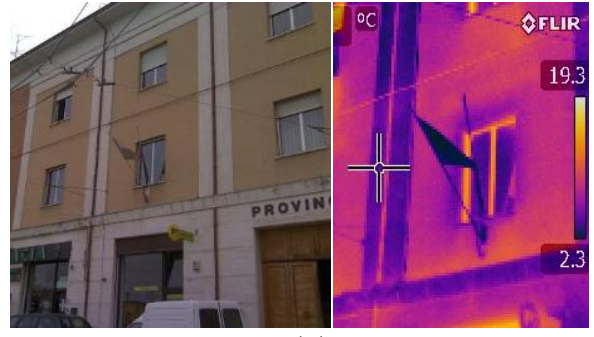

(a)

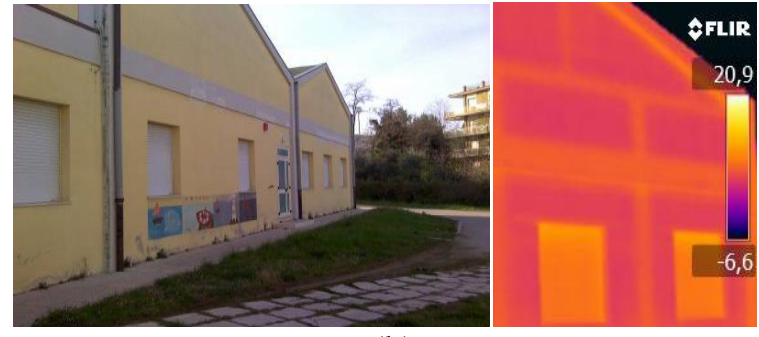

(b)

Figure 5. Infrared thermography (IRT) carried out during energy audit activities: Province of Chieti office building at Chieti (a); Nursery School "S. Giuseppe" at Ortona (b)
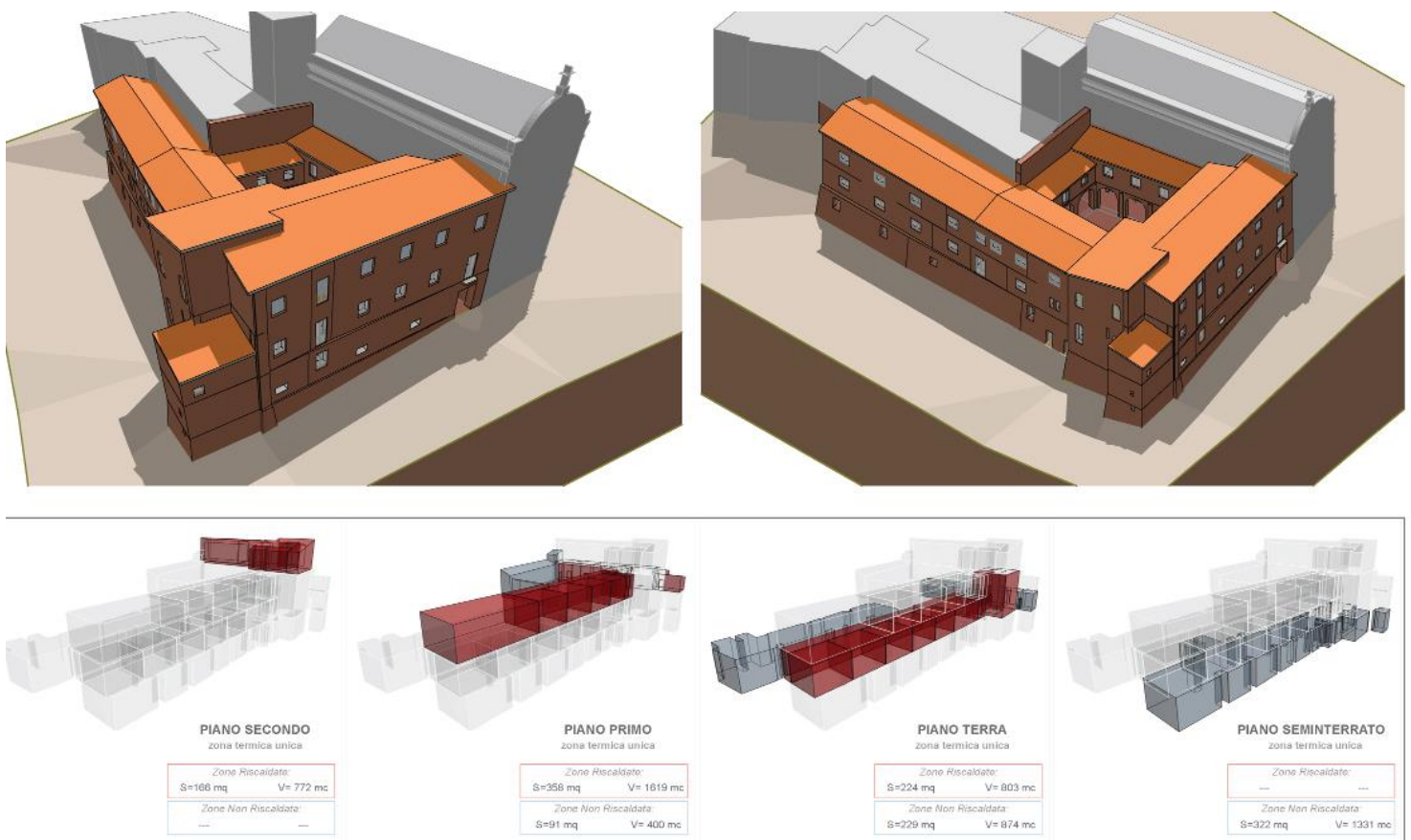

Figure 6. 3D model of thermal analysis of the city hall building in Bucchianico municipality performed during energy audit activities (courtesy: Landbau srl)

Some public buildings are used and directly managed by private companies, entities and associations that directly pay for the costs of energy consumption. This is particularly noticeable in sporting complexes (swimming pools, indoor sporting facilitiesm, etc.) and local Police Stations including their living quarters. In such situations, energy efficient measures would not take advantages to public bodies.

Underused or not-used public buildings represent a problem in order to effectively draw up energy consumption consistency and baseline for further technical and economical considerations.

Moreover, building ownership is a critical issue. Some buildings are next to being transferred by the public owner or have an uncertain future about certain function and use for public services. This is the case, for example, of many large public buildings that currently host court and judicial offices and authorities. In fact, due to drastic reductions 
in expenditure, current legislation imposes relocations and mergers with reorganization and rationalization of offices.

A certain number of buildings have an energy reduction potential related to interventions that have a payback time over 15 years. This is a typical situation which occurs considering actions on building envelope parts such as additional insulation on roofs and walls and windows replacement. In most cases, especially in not so cold climate sites and with low energy consumption in absolute terms, this kind of interventions are not effective for EPC contract schemes and need further public investments with different financial instruments than ELENA.

More generally, to be excluded are a certain number of public buildings originally included in the Project and classified by preliminary audits as not adequate to the Project requirements and conditions. In Table 1, Municipalities and Province property buildings involved in the Project are listed by type.

Table 1. Buildings included within the "Chieti Towards 2020" Project

\begin{tabular}{cccc}
\hline Type of public building & Municipalities property & Province of Chieti property & Total \\
\hline Schools & 84 & 41 & 125 \\
Offices & 22 & 3 & 25 \\
Sporting complexes & 21 & - & 21 \\
Court rooms & 2 & - & 2 \\
Social & 3 & - & 3 \\
Museums & 2 & - & 2 \\
Libraries & 2 & - & 2 \\
Theaters and Auditorium & 4 & - & 4 \\
Other & 4 & - & 4 \\
\hline Total & 144 & 44 & 188 \\
\hline
\end{tabular}

\section{Communication skills, dissemination of experiences and results}

As previously mentioned, one of the most important problems of this kind of projects is the "transfer of sustainability" issues from global to local scale, trying to overcome resistance and inefficiencies of public bodies that are often closed and, in substance, refractory to changes. Lack of clarity and thoroughness in communications, misunderstandings and time-consuming for the exchange of information might undermine even the best efforts made at technical level and endanger the overall success of the project. This risk deals also with lack of awareness about EPC among public decision-makers and civil servants.

Thus, during the Project's development, the need for a well-structured program of communication, engagement and dissemination of results has clearly emerged.

Starting from the early stages and Project start up and across the Project's development, some communication and information events have been organized, engaging municipalities and professionals at the local level:

- Information meetings with all the Mayors and councils technical staff of Municipalities involved into the project;

- Training and informative meetings with professionals in charge of audits on buildings' public lighting;

- Collaborative meetings with all the Mayors and councils technical staff of Municipalities involved in the project, in order to explain Energy Performance Contract mechanisms and details and to undersign confidential agreements about Call of Tender Terms of References. 
However, in spite of a great effort spent for the information and involvement of municipalities, energy audits and general coordination actions have encountered difficulties and resistance. One of the major problems experienced during the technical auditing and coordination activities was the difficulty to communicate and share information with the technical reference persons appointed by the Local Councils. A poor attitude in cooperating during data collection activities and a reluctant trend in releasing copies of documents, information and data about the management of their buildings, lighting systems and maintenance contracts and agreements, were consistently and frequently encountered. It was also very evident that there was not only a lack about detailed knowledge and awareness of energy efficiency of the buildings they were responsible for, but also inefficient procedures for recording and storage of energy bills and supply documentation.

In order to overcome these difficulties in a short time, communication channels have been activated with the ELENA internal staff, which acts as "facilitators" between municipalities and energy auditors. Considering the number of municipalities involved and the small dimensions of most of them, it was unavoidable that certain problems and inconveniences would have emerged. In this case, the best strategy, that immediately shaped positive effects, was to adapt solutions to individual problems and situations, pursuing strictly dialogue and feedback with each municipality.

Those resilient situations could be repeated, especially during the implementation phases in which ESCOs will act directly with municipalities on audits and facilities management. For this reason, it will be necessary to go through continuous information and communication skill-building of staff and administrators, local and national stakeholders and local communities. Further steps will then consist of the following:

- Publish and disseminate the content of the ELENA facility and the implemented plan;

- Provide full information to municipalities and to the general public on the results achieved by interventions throughout the implementation period;

- Inform also on the phases of management, monitoring and evaluation of interventions and their used funds.

\section{PROJECT'S IMPLEMENTATION STATUS AND FIRST RESULTS}

The project's activities carried out to date lay the foundations for further advancement, such as call of tender phases. In fact the energy audits on public buildings are almost completed and the general framework is quite clear about the type of investments and energy saving potential to discuss relevant numbers and results.

Energy audit activities on public lighting systems, involving 71 Municipalities have been divided into two steps: the first stage is completed by external experts and concern Municipalities with 24,877 light points. The second group of audit reports activities are still undergoing and refers to 49 Municipalities divided into 3 distinct and separate functional lots for a total of approximately 21,382 estimated light points.

The 21 auditing reports on 144 municipalities buildings were completed and submitted to the ELENA offices by the external experts who produced reports and annexes, such as data, information, drawings, photographs, graphs and spreadsheet information in order to facilitate energy efficiency standards and evaluation. It is the largest energy audit action carried out on public buildings in the Abruzzo Region and one of the largest ever done in Italy.

After the completion of the energy efficiency auditing activities, the Procurement Notice for the pre-qualification of candidates was published for the assignment of a concession contract for goods and services for the realization of energy efficiency 
measures. The management includes preliminary and detailed project design, the implementation of EE measures, the management and maintenance of the buildings involved as well as the supply of energy commodities as required for the duration of the contract (15 years).

The concession has the aim of generating investments to reduce energy consumption and costs of at least $20 \%$ to the majority of the buildings included in the selection as identified in the letter of invitation to be sent to the pre-qualified candidates.

The Contract Awarding Criteria table (to be disclosed only after completion of pre-qualification procedures) allocates points to candidates rewarding technical and financial offers that focus attention on energy efficiency investments as well as assign points to candidates that offer energy supplies at a lower price than that market reference benchmarks and RES implementation over a certain percentage in respect to total primary energy consumption baseline. The maximum allowed duration for EPC contract is 15 years. This means that all EE and RES interventions carried out by ESCOs during this period need to be sustainable from the financial point of view, with a payback time well lower than 15 years. Such a goal is easily achievable acting on out-of-date heating and lighting systems that need renovation in high energy consumption buildings. On the other hand, the economic viability of retrofit interventions on building envelope (walls, roofs, windows) depends strongly on local climate factors. In the temperate mediterranean climate, where the Province of Chieti territory is located, payback time about envelope retrofit generally exceeds 12-14 years and it represents a serious obstacle for ESCOs in implementing such kind of interventions.

For this reason, in the realization of energy efficiency measures in five public buildings, the Province of Chieti will use European Regional Developing Fund for EUR 500,000 in order to assure the feasibility of pay-back of investments involving building envelope, through reduced consumptions and costs within the 15 year period. This is an innovative approach to face above mentioned barriers and, to date, limited to just a test group of buildings in order to verify the effectiveness through the ESCOs' market response.

With regards to the public buildings property of the Province of Chieti, there are 44 buildings that have been included in the auditing activities, 41 of which are schools and 3 are institutional locations for administrative activities and offices. Of these, a total of 15 audit reports are being completed and the others are still in progress.

Table 2 shows thermal and electrical energy consumption mean values, grouped by building type, as collected through energy audits and which represent the baseline scenario for energy efficiency interventions. The overall energy demand for space heating and Hot Water (HW) production is 84,181 GJ, while the electrical energy consumption is $5,415.061 \mathrm{kWh}_{\mathrm{e}}$.

It is interesting to note (Figure 7) that buildings hosting schools and public offices are the main energy consumers. In detail, schools are responsible for $79.2 \%$ of heating and hot water energy consumption and $67.4 \%$ of overall electrical energy consumption. These results are quite aligned with similar studies carried out in Italy [15] and appear as fundamental information in order to correctly address interventions and in-depth strategies and policies, both at the local and national level.

Other useful information about the energy "health" of buildings and energy saving potential come from benchmark analysis results. The mean energy performance index $(E p)$ for heating for schools is about $94 \mathrm{kWh} / \mathrm{m}^{2}$ year, while administration offices have an $E p=67 \mathrm{kWh} / \mathrm{m}^{2}$ year. A recent research has showed that a typical benchmark value for similar school buildings stock in Italy is $114 \mathrm{kWh} / \mathrm{m}^{2}$ year [19]. If we consider that energy efficiency measures could set benchmark up to $30 \mathrm{kWh} / \mathrm{m}^{2}$ year, it is possible to estimate 
a great potential for energy saving in that type of buildings, even if values and percentages may vary significantly according to local climate conditions and construction features.

The audit activities on public lighting system are still under execution, as above mentioned, but a first group of 22 Municipalities is already completed. The information provided on a total of 24,877 light points shows an average energy saving potential of about $25 \%$, achievable through a variety of interventions, such as lamps substitution or light flux reduction strategies. The expected investment for the first call for EPC for Municipality public lighting is EUR 4.75 million while the overall maintenance costs, as stated in the baseline, is around EUR 500,000.

The next development stages of "Chieti Towards 2020" Project within 2014, concern the completion and assessment of energy audit activities on lighting systems, the preparation of documents for further calls for tenders, tenders execution and start of ESCOs contracts and interventions.

Table 2. Energy Consumption of municipalities' buildings (mean values 2010-2012 period)

\begin{tabular}{|c|c|c|c|c|c|c|}
\hline \multirow{2}{*}{$\begin{array}{l}\text { Type of } \\
\text { public } \\
\text { building }\end{array}$} & \multicolumn{2}{|c|}{$\begin{array}{l}\text { Municipalities } \\
\text { property }\end{array}$} & \multicolumn{2}{|c|}{$\begin{array}{l}\text { Province of Chieti } \\
\text { authority property }\end{array}$} & \multicolumn{2}{|c|}{ Total } \\
\hline & $\begin{array}{c}\text { Heating } \\
\text { and HW } \\
{[\mathrm{GJ}]}\end{array}$ & $\begin{array}{l}\text { Electricity } \\
{\left[\mathrm{kWh}_{\mathrm{e}}\right]}\end{array}$ & $\begin{array}{c}\text { Heating } \\
\text { and HW } \\
{[\mathrm{GJ}]}\end{array}$ & $\begin{array}{c}\text { Electricity } \\
{\left[\mathrm{kWh}_{\mathrm{e}}\right]}\end{array}$ & $\begin{array}{c}\text { Heating } \\
\text { and HW } \\
{[\mathrm{GJ}]}\end{array}$ & $\begin{array}{l}\text { Electricity } \\
{\left[\mathrm{kWh}_{\mathrm{e}}\right]}\end{array}$ \\
\hline Schools & 34,876 & $1,340.489$ & 31,765 & $2,311.926$ & 66,641 & $3,652.415$ \\
\hline Offices & 4,780 & 648,023 & 1,351 & 274,875 & 6,131 & 922,898 \\
\hline $\begin{array}{l}\text { Sporting } \\
\text { complexes }\end{array}$ & 365 & 391,343 & - & - & 365 & 391,343 \\
\hline Court rooms & 7,289 & 3,851 & - & - & 7,289 & 3,851 \\
\hline Social & 1,595 & 81,334 & - & - & 1,595 & 81,334 \\
\hline Museums & 534 & 106,555 & - & - & 534 & 106,555 \\
\hline Libraries & 492 & 24,604 & - & - & 492 & 24,604 \\
\hline $\begin{array}{l}\text { Theaters and } \\
\text { Auditorium }\end{array}$ & 0 & 107,873 & - & - & 0 & 107,873 \\
\hline Other & 1,134 & 124,188 & - & - & 1,134 & 124,188 \\
\hline Total & 51,063 & $2,828.260$ & 33,116 & $2,586.801$ & 84,181 & $5,415.061$ \\
\hline
\end{tabular}
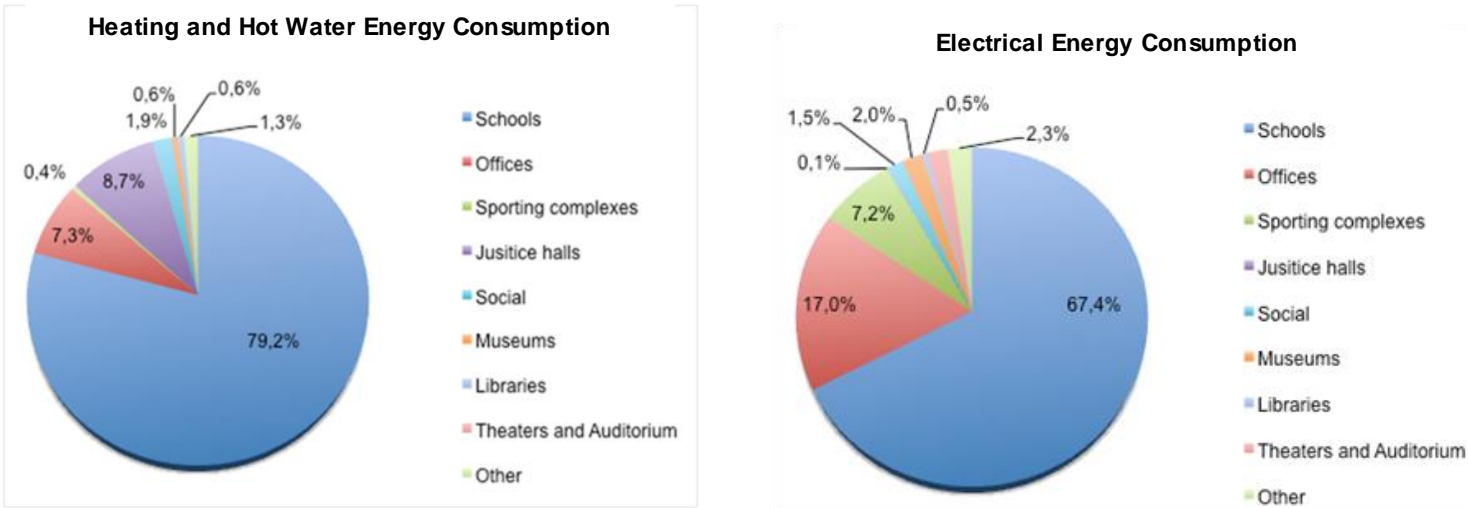

Figure 7. Heating, hot water and electrical energy consumption breakdown by building type 


\section{CONCLUSIONS}

The "Chieti Towards 2020 project" is still ongoing, even with the exclusion of the previously expected photovoltaic investments with consequent reduction of EUR 20 million from total project investments due to changes in Italian incentive framework. Activities carried out to date, put an important milestone to further development steps and improvements to become a best practice framework to be adapted to other contexts with comparable features and extension. A first acknowledgment for the job done by the Province of Chieti has come with the nomination received for the final run of Sustainable Energy Europe ManagEnergy Local Energy Action Award, held in Brussels from 24 to 28 June 2013.

The model explained in this paper appears to be effective especially in territories with low population density and infrastructure, which becomes even more important trying to operate an efficient "glocal" synthesis to achieve the success of PPP initiatives in the field of energy. A mixed approach between bottom-to-top and top-to-bottom strategies seems to be very effective. Some well known barriers and obstacles to PPP framework in EE investments have been faced and, in some cases, successfully solved especially through technical, economic, legal, and communication skills.

One of the most important lessons learnt is that complex and wide projects such as ELENA require an adaptive and "fluid" problem-solving approach. It is necessary to carry out a constant review of the procedures and timing while the different project steps are implemented. In fact, some variables such as the technical and regulatory framework, the social and economic conditions and the ESCOs market, change quickly and following the trends is not easily predictable. Furthermore, we experienced that not all the possible actions of energy reduction are achievable using an EPC mechanisms within a PPP framework, especially those with payback time not suitable for investment feasibility. For these interventions, starting from a solid knowledge of limits and possibilities through energy audits, it appears necessary to find other kinds of public financial and intervention schemes.

\section{REFERENCES}

1. International Energy Agency, Energy Efficiency Governance, Paris, 2010.

2. International Energy Agency, Joint Public-Private Approaches for Energy Efficiency Finance, Paris, 2011.

3. European Investment Bank, Public-Private Partnerships in Europe: Before and During the Recent Financial Crisis, Luxembourg, 2010.

4. Bertoldi, P. and Rezessy, S., Energy Service Companies in Europe: Status Report, European Commission, DG JRC, 2005.

5. Bertoldi, P. and Rezessy, S., Financing Energy efficiency: Forging the Link Between Financing and Project implementation, DG JRC, 2010.

6. Mayer, A., Energy Performance Contracting in the European Union: Introduction, Barriers and Prospects, Johnson Controls, Washington, 2010.

7. European Investment Bank, Energy Lending Criteria, Luxembourg, 2013.

8. Shelanski, H. A. and Klein, P. G., Empirical research in Transaction Cost Economics: A Review and Assessment, Journal of Law, Economics and Organisation, Vol. 11, No. 2 , pp 335-361, 1995.

9. Rindfleisch, A. and Heide, J. B., Transaction Cost analysis: Past, Present and Future Applications, Journal of Marketing, Vol. 61, No. 4, pp 30-54, 1997,

10. Buckley, P. J. and Chapman, M., The Perception and measurement of Transaction Costs, Cambridge Journal of Economics, Vol. 21, pp 127-145, 1997, http://dx.doi.org/10.1093/oxfordjournals.cje.a013663 
11. Peretz, N., Growing the Energy efficiency Market through Third-party financing, Energy Law Journal, Vol. 30, pp 377-403, 2009.

12. Zabot, S. and Di Santo, D., Guida ai contratti di prestazione energetica negli edifici pubblici, ENEA, 2013.

13. Latouche, S., Come sopravvivere allo sviluppo, Dalla decolonizzazione dell'immagianrio economico alla costruzione di una società alternativa, Bollati Boringhieri, Torino, 2005.

14. Purvis, M. and Grainger, A., Exploring Sustainable Development, Geographical Perspectives, Earthscan, London, 2004.

15. Elliott, D., Energy, Society and Environment, Routledge, London, 2004.

16. Dall, O. G., Green Energy Audit, Edizioni Ambiente, Milano, 2011.

17. Conti, P., Della Vista, D., Fantozzi, F., Fasano, G., Grassi, W., Manetti, R., Menchetti, E., Schito, E., Signoretti, P. and Testi, D., Definizione di una metodologia per l'audit energetico negli edifici ad uso residenziale e terziario, ENEA, 2011.

18. Thumann, A. and Younger, W. J., Handbook of Energy Audits, Seventh Edition, 2007.

19. Corgnati, S. P., Fabrizio, E., Ariaudo, F. and Rollino, L., Edifici tipo, indici di benchmark di consumo per tipologie di edificio, ad uso scolastico (medie superiori e istituti tecnici), applicabilità di tecnologie innovative nei diversi climi italiani, ENEA, 2010. 